\title{
In the best interests of the deceased: A possible justification for organ removal without consent?
}

\author{
Govert den Hartogh
}

Published online: 19 May 2011

(C) The Author(s) 2011. This article is published with open access at Springerlink.com

\begin{abstract}
Opt-out systems of postmortem organ procurement are often supposed to be justifiable by presumed consent, but this justification turns out to depend on a mistaken mental state conception of consent. A promising alternative justification appeals to the analogical situation that occurs when an emergency decision has to be made about medical treatment for a patient who is unable to give or withhold his consent. In such cases, the decision should be made in the best interests of the patient. The analogous suggestion to be considered, then, is, if the potential donor has not registered either his willingness or his refusal to donate, the probabilities that he would or would not have preferred the removal of his organs need to be weighed. And in some actual cases the probability of the first alternative may be greater. This article considers whether the analogy to which this argument appeals is cogent, and concludes that there are important differences between the emergency and the organ removal cases, both as regards the nature of the interests involved and the nature of the right not to be treated without one's consent. Rather, if opt-out systems are to be justified, the needs of patients with organ failure and/or the possibility of tacit consent should be considered.
\end{abstract}

Keywords Organ donation · Opt-out system · Best interests ·

Presumed consent · Volenti

\section{Introduction}

Legal systems of the procurement of postmortem organs for transplantation are usually classified into opt-in and opt-out systems. Systems of both types aim to

G. den Hartogh (ه)

Department of Philosophy, University of Amsterdam, Oude Turfmarkt 141-147, 1012, GC,

Amsterdam, The Netherlands

e-mail: G.A.denHartogh@uva.nl 
respect the decision of the deceased person, whether her decision was to donate, to refuse donation, or to hand over the decision to her relatives (or to some other person). The basic difference between these systems of organ procurement concerns what they take to be the default when the deceased did not make any decision at all. In pure opt-in systems the default is that no removal of organs will take place; in opt-out systems, the default is that it will take place. In the systems commonly known as opt-in systems, however, the actual default is that the decision will be made by the family of the deceased. Hence, a threefold classification would be more accurate than the present one.

It is usually supposed that opt-out systems tend to have better results in terms of organs becoming available for transplantation than opt-in systems, even the imperfect opt-in systems. This is a complex and contested issue, which I cannot enter into in this article. ${ }^{1}$ My own middle-of-the-road view is that a legal opt-out system can be an important part of a package, with other elements of the package, such as the identification of potential donors and the method of approaching their relatives postmortem, being (at least) as important; this package, as a whole, tends to have better results. The legal system is important because in decision-making, people generally tend to keep to the default, whatever it is, unless they have clear and unambiguous reasons to deviate from it [4-6]. This is true both for people considering whether to register a decision to donate or a refusal of donation and for their surrogates when they are being asked to decide in cases in which the deceased did not make a decision.

Even recognizing this advantage, however, legislative majorities in many jurisdictions have refused to introduce an opt-out system. The main objection to optout systems has always been that in such systems it is possible for people to have their organs removed after their death without their consent or even against their wishes. Oddly enough, people who voice this objection usually fail to observe that it applies equally to the actual opt-in systems they prefer, because in such systems, the default is not that no removal of the organs will take place but that the family will decide whether it will or not. If in such a case the family decides to consent to removal, this is done without consent of the deceased and possibly against his wishes. Nevertheless, the objection to opt-out systems should be taken seriously. Is it possible to defend opt-out systems against it?

I will assume without further argumentation that the requirement of consent follows from a right of people to make decisions about the way other people may act with respect to their bodies, both before and after their death. An obvious way of defending opt-out systems is to note that this right is limited. The ways to dispose of a corpse before it starts decaying are essentially limited to burial or cremation. This limitation is primarily justified by the harm principle: having corpses lying around is a threat to public health. ${ }^{2}$ But it is also usually assumed that the state is authorized to command autopsies without the consent of the deceased or his relatives in the interests of other people. It could be argued along similar lines that the interests of

\footnotetext{
1 The better results of opt-out systems have been disputed; see, e.g., [1-3].

2 Some limits may rather be motivated by considerations of human dignity, e.g., the prohibition against feeding one's dead body to the tigers in the zoo.
} 
patients suffering from organ failure justify the removal of someone's organs after his death for the ends of transplantation. I will not consider this possible justification in this article.

Probably the best-known way to justify opt-out systems is by reference to the presumed consent of the deceased; in the English-speaking world "presumed consent" is almost a proper name for such systems. Presuming someone's consent appears to mean holding him to have consented in the absence of compelling evidence that he actually has [7]. The usual reason provided for assuming consent is that the system can err on both sides (by removing the organs of someone who did not consent or by not removing the organs of someone who did) and that the probability of the second error is the greater. However, this view depends on the equation of "consent" with a mental state of desire or preference. The requirement of consent in that case is implied by a principle of maximizing the satisfaction of people's interests, broadly conceived as the fulfilment of their preferences. But if a person has the right to decide about the fate of her own body, that means that her decisions are authoritative and, therefore, preempt other people's weighing of her interests. By consenting or refusing to consent, she does not merely reveal her preference but exercises her authority. Consent, in this context and similar ones, therefore, does not refer to a mental state, but to a public act with normative consequences. Hence, the common criticism of presumed consent is correct: by its nature the requirement of consent can only be fulfilled by compelling evidence that it actually has been given. Probabilistic evidence that a person would have preferred to donate is not enough. ${ }^{3}$

In this article, I want to consider another possible justification of opt-out systems. According to this alternative argument, we should act on our judgment of the best interests of the deceased directly, without masquerading this judgment as an appeal to presumed consent. In this enterprise, there really is no safe side to err on: it is deplorable that one person's organs are left unused when he preferred to donate them, and it is equally so that another person's organs are removed when he did not want to donate them. So one is justified in considering which of these two alternatives is the most probable one.

But how can acting in the interests of the deceased without his consent be compatible with his authority over his dead body? The suggestion to be considered is that the requirement of consent only applies when certain important conditions have been satisfied, but these conditions cannot be satisfied when the decision about organ removal has to be made and the deceased has not exercised his authorityright, either by consenting or by refusing. ${ }^{4}$

Why am I interested in this possible justification? In the first place, it has been ably advocated in the literature. ${ }^{5}$ More importantly, it seems to be the most promising way to defend opt-out systems against the objection that they fail to satisfy the requirement of consent. It is certainly far more plausible than a

\footnotetext{
3 I have elaborated on this argument in [8].

4 A final possible justification of at least some opt-out systems is an appeal to tacit consent, on the assumption that it can be a species of actual and genuine, not merely presumed, consent [9].

5 See, e.g., David Price [10, Chap. 5] and Martin Wilkinson [11].
} 
justification in terms of presumed consent. In introducing opt-out systems, legislative authorities usually appeal to the fact that, in surveys, $80-90 \%$ of the population testify to a positive attitude concerning postmortem organ donation, and this is taken to show a preference for donation. ${ }^{6}$ If such preferences cannot be interpreted as constituting consent, maybe they can be appealed to directly.

\section{Appealing to the best interests of the patient}

In opt-out systems, organs are routinely removed from people's dead bodies without their consent. Critics often conclude that if people's right to make authoritative decisions about their own bodies implies that consent is required, that right is being frequently infringed. On the view I want to consider, that conclusion does not follow. Suppose that the holder of any authority-right is disabled, temporarily or permanently, and cannot exercise the right to give consent; suppose also that she has not given consent in advance before being disabled. What should we say? The present case-let me call it the organ removal case-is of this kind: if we only take into account moral considerations regarding the rights and interests of the deceased, it is clear that if she had registered a valid consent before she died, we would be allowed to proceed, and if she had registered a refusal, we would not. But what if she registered neither consent nor refusal?

In such cases, there are two options. We could hold that we should now directly consider the person's interests because they cannot be represented by her own authority. If this leads us to the removal of the deceased's organs, lawyers may even say that we acted on "imputed consent," meaning that even if consent was lacking, we were justified in acting as if the person had consented because, on justificatory grounds, the person's best interests were as good as her consent [10, pp. 140-148; 13 , p. $187 ; 14] .{ }^{7}$ Or we could hold that the normative barrier to entering the person's private domain, since it was not lifted by her, is still in place. Which of these options should we prefer? We should not assume without further examination that there is a general answer to this question. The requirement of consent may sometimes still be relevant, and sometimes not. Let me therefore consider, in good casuistic fashion, an example of a situation in which the consent requirement is not relevant anymore and then compare the organ removal case to it.

The notion of presumed consent is standardly used in medicine when it is impossible to ask a patient for informed consent, for example, if a patient is temporarily unconscious as a result of an accident. On the conception of consent I have defended, the term is misleading, if not improper, for what we can presume is not that authorization has actually been given, but at best, only that it would have been given if the person had been able to make a decision. Hence, what we really mean by presumed consent is that medical decisions in such cases should be guided by the best interests of the patient, and in particular, that we should understand her

\footnotetext{
${ }^{6}$ It is doubtful whether this really is what the survey results shows: people may combine a generally favourable attitude with individual doubts and hesitations [12, §4].

7 Feinberg calls evidence of a person's wishes a "consent surrogate."
} 
best interests in terms of her personal values, not our own [3, p. 11; 15]. (For example, in the case of many patients, the mere chance of survival in a severely handicapped mental state will not justify keeping them alive in a persistent vegetative state). But we should not say that in making such judgments, we are exercising her right to make decisions about her own body in her place. Nor should we say that such judgements override her right to make decisions. Rather, the right itself should be understood in such a way that it does not stand in the way of such judgments. The right could, for example, be taken to mean that we should not initiate any medical treatment without the patient's consent if he is able to give it competently.

If something like this is the proper specification of the right, could not we argue in a similar way that the postmortem removal-under proper conditions-of organs for transplantation without the deceased's consent is fully compatible with the requirement of consent and the right from which it follows? The justification of introducing an opt-out system could then take the following form: the available evidence suggests that in the majority of cases in which no decision of the deceased has been registered, it is in his best interests to have his organs taken out for transplantation. We will often err in acting on that assumption, but we will more often err in acting on the contrary assumption. And by aiming to act on the best interests of the deceased we do not contravene his authority, for being dead, he can no longer exercise it.

This line of reasoning would still leave us with a burden of proof that may be hard to meet in actual cases. ${ }^{8}$ Research has shown that the very fact that people do not register any decision tends to reveal an attitude of either indifference or ambivalence. ${ }^{9}$ If that is true, we will not increase the probability of fulfilling their wishes by removing their organs. But let us suppose that we will in a particular case. Is it then open to us to follow this line of reasoning?

\section{A suggestive difference: Does Volenti hold?}

I believe there are a number of significant differences that make it doubtful whether we can argue in similar ways in both the emergency and the organ removal cases. I will start by pointing out a difference that exists even when the will of the patient has been expressed in an authoritative way. Consider the emergency case: even if the patient has given permission, in a legally binding document, to be treated under the circumstances that presently obtain, he has not provided necessarily a sufficient justification for treating him. On our usual (albeit increasingly contested)

\footnotetext{
${ }^{8}$ Actually, if we are trying to maximize interest satisfaction, we should not only consider the number of cases in which our assumptions are mistaken or not, but if they are, also the extent to which they are mistaken, i.e., the weight of the interests involved. Do we harm people to the same extent if we take their organs against their wishes or if we do not take them? Another complicating factor is that people's welfare interests may not be identical with the fulfilment of their actual wishes: these wishes should perhaps be "laundered" in some way. These very complications may be part of the rationale for leaving the authority to decide with the agent.

9 See [8, §4] for a summary and references.
} 
understanding of the professional ethics of doctors, a doctor cannot justify actions that are actually harmful to the patient by appealing to the patient's consent. In this domain, the maxim volenti non fit iniuria (no injury is done to a person who consents) has only a limited validity. But if a decision to donate is made in a competent way, no one ever has any qualms about applying the Volenti principle whatsoever. ${ }^{10}$

As for the emergency case, if a person's survival is at stake, we have reason to be very cautious in judging that survival will be harmful if she does not think so herself; this is so because of the extent to which such judgments depend on personal values. In the next section, this will turn out to be a highly relevant consideration (cf. [17]). But if an advance directive requests a form of treatment which is not lifeprolonging and which, both in the personal judgment of the doctor and of the "professional standard," is considered harmful to the patient, consent will not be enough to justify treatment. This is also the case if treatment lengthens life only for a short time, if the patient during that time will be in a state of severe suffering or if the additional burdens caused by the treatment will be heavy.

We can point to the same difference between the two cases in the following way. If a certain form of treatment is medically indicated and the patient consents to it, a doctor has a professional duty to the patient to treat the patient in that way. If the patient is unable to give consent, it is still a perfect duty. But if a person consents to have her organs taken out for transplantation after her death, doctors have no duty, at least no duty to her, to remove them [18]. And, a fortiori, they do not have that duty if she dies without having made a decision.

I have started with this difference between the emergency case and the organ removal case because it suggests other differences and obviously depends on them. To identify these other differences, we could look in either of two directions, or in both. In the emergency case, no actual consent of the patient is needed, because the right to make decisions concerning treatment, which normally requires such consent, is limited by the patient's interest in being treated. So for a more basic difference with the organ removal case, we can look either to the nature of the right involved or of the interests limiting it. In fact, I believe we will find relevant (and related) differences on both sides.

\section{The first basic difference: The nature of the interests involved}

Firstly, take the interests that are supposed to be limiting ones. In the emergency case, these belong to a special category of interests that we could call basic needs: survival, health, freedom from injury. The class of basic needs is notoriously difficult to demarcate, but there are clear cases on the side of both basic needs and mere personal preferences. Emergency cases quite often concern clear cases of basic needs. Indeed, it is because basic needs are at stake that health care is special, a matter of social concern. But satisfying the personal preferences of a person is an undertaking that we normally believe the person should take care of herself. This is

${ }^{10}$ Cf. my discussion of the Volenti principle in [16]. 
not necessarily because these preferences are less important to the patient than basic needs: people may sacrifice their health and even their lives for other priorities. Rather, because these other priorities depend on the patient's own values in a way that makes them part of her identity as a person, we leave her to pursue them in her own way and by her own lights. A person could not reveal, and perhaps not even have, values if she did not pursue them in ways that involved making costly choices (cf. [19, pp. 115-116]). ${ }^{11}$ Most people would agree that providing, up to a certain threshold, people with the all-purpose means (including health care) needed "to subscribe to, to revise, and to actively pursue a conception of the good," to use Rawlsian phraseology, should be a social concern. But we leave it to them to pursue their own conception of the good. ${ }^{12}$

If people had the same kind of interests in having their organs taken or not taken as they have in being treated or not treated in emergency cases, and if we could identify the interests of the majority, I agree that we should act according to those interests, by choosing our default accordingly to begin with. But although basic needs are at stake in the organ removal case as well, they are other people's basic needs, not our own. Perhaps we have moral duties to help these needs to be met, if we can, but we cannot say that it is in our own personal interest to fulfill them. Whether or not it is in our interest fully depends on what we really care about. For most people who care about donation, this care is not very central to the projects and relationships that determine the personal value of their lives. ${ }^{13}$ (Although it may be implied by the basic attitudes they have towards life in general). Occasionally, it may be of great importance for a person to be able to donate, for example, if she believes that this will be the only way to redeem a wasted life. But in such a case it is still fully up to her to make up her own mind and to take care of what she cares about. ${ }^{14}$

\section{The second basic difference: The nature of the right involved}

My conclusion about interests is confirmed when one considers the right. In the emergency case the right involved — not to be treated without one's own consent-is an aspect of the inviolability of the body. Like many other rights, this should be interpreted as a bundle of rights, powers, and/or immunities. One of those "atomic" rights, which is a constitutive element of the bundle, is an authority-right to decide

\footnotetext{
11 This is not inherently a deontological view; it can be shared by any kind of consequentialism which values autonomy and/or allows for a moral division of labour.

12 Rawls famously argued that people are responsible for their "expensive tastes" [20, p. 94, 261-263, $423 ; 21]$; see also [22, 23, Chap. 1]. But if one is able to change one's religion because it becomes too costly to satisfy its demands, one never was a believer in the first place. It is not because people can choose their values that we make them responsible for the costs involved in pursuing them.

13 This tends, of course, to be particularly true in the cases in which people fail to have registered a decision. The weight of such (personal) interests is not great enough to make their satisfaction a matter of social concern.

14 On this point, I disagree with David Price when he says that the neglected wish to donate is "no less a wrong" to the deceased than the overridden wish to refuse donation [10, p. 147] In most cases it is a very minor harm, and in all cases in which the harm is greater, it is open to the deceased to avoid it. Hence it is never a wrong.
} 
about access to one's body. But this cannot be all there is to the right to bodily inviolability, for in that case we would have no problems in allowing the Volenti maxim to apply to it without any restrictions. Surely another "atomic" constituent of the right is simply the correlate of other people's duty not to cause bodily harm to others. ${ }^{15}$ The right is meant to protect others not only from a lack of recognition but also from injury. ${ }^{16}$ This protection is paradigmatically one of people's basic needs. And this explains why the right does not block even actions that harm the person who bears that right, if these actions are necessary to prevent much greater harm to her and if it is not feasible to consult her.

It is often supposed that the right to make decisions about our own dead bodies is identical to the right to bodily integrity as it extends after our death [26]. In some countries, this view even has legal status. ${ }^{17}$ But T. M. Wilkinson has convincingly argued that the view is implausible [27]. As he says, the right to bodily integrity is one of our basic rights because we are embodied beings, but my dead body is no longer an embodiment of "me."

It is plausible that we-living people of course, not dead ones-have the authority-right to make some binding decisions concerning what will happen to our bodies after our death. Indeed, that we have such rights is essential to my argument, for if posthumous wrongs could not exist, it would not make sense to require the consent of the deceased for the removal of his organs. Neither do I dispute the possibility of posthumous harms. For example, some people have a preference for their bodies to remain intact for some time after their death. However, this preference cannot be compared to the interest in being free from injury during one's life. Injuries cause pain, suffering, and handicaps, but interfering with a dead body causes neither of these harms. Any harm which it causes can only be a posthumous harm, for example, by affecting the way the person will be remembered. Whether people have such preferences is a highly contingent matter; it depends on their general outlook on life, and certainly is not a matter of "basic needs." If it were, it would only be possible to meet it for a very short time.

Therefore, if there is any continuity between our right to bodily integrity and our right concerning our dead body, it can only concern one particular atomic element of the first right (the authority-right), not the other element (the freedom from injury). And because we should not take for granted without argument that this authority-right has either the same scope or the same weight before and after death, we should not make too much of the continuity either. Rather, one's right to make decisions about the destination of one's own dead body should be seen as a right of its own, only belonging to the general class of authority-rights, i.e., one's body, even one's dead body, is preeminently one's own-part of the private domain over which

\footnotetext{
15 On the long-standing discussion about the appropriateness of either a choice-theory or an interesttheory of rights, my view is that there are rights, or elements of rights, of either class. For a classical review of the discussion, see [24].

${ }^{16}$ James Griffin argues that the right not to be tortured protects our freedom to withhold information [25, pp. 52-53], which is unconvincing for the same reason.

${ }^{17}$ E.g., Germany and the Netherlands. The relevant article in the Dutch constitution (Art. 11) has been introduced with this application in mind, and for some time, opt-out systems have therefore been rejected as "unconstitutional."
} 
the individual is sovereign. The harm one suffers if that right is being violated is the harm of disrespect. The prevention of that harm is a social concern, the prevention of other possible harms involved is up to the individual.

Why is sex with an unconscious person impermissible if he or she did not previously consent to it? One could use the emergency case as an analogy, and argue that the reason is that people are less likely to want than not want to have sex while unconscious, and that the first want is also probably the strongest of the two. But that does not seem to be the heart of the matter. Even if one had accidentally come across some reliable evidence allowing one to assume that the person wished to have sex while unconscious with someone like one (perhaps one accidentally overheard a conversation between her and her psychiatrist), it would be rape to actually have sex with her. Maybe it will do no harm to her welfare interests, but it will still violate her rights, and thereby harm her interests in dignity.

It could be argued that no evidence can really be trusted in such cases: there is a difference between having certain fantasies about possible cases and preferring these fantasies to be actually enacted, and there even is a difference between having a conditional preference and having an actual preference if the condition is satisfied. But this is rather part (and surely no more than a part) of the explanation as to why people have an authority-right concerning access to their body in the first place, and so it concedes the point I want to insist on: when consent can no longer be given, nothing has changed to make it redundant.

I believe the same point generally applies to organ removal cases, ${ }^{18}$ but its force is strengthened in cases where it is feasible to ask for people's consent while they are alive. When this is feasible but has not been done, any appeal to our presumed preferences after our death would be in a kind of bad faith. We might say, "we have some reason to believe that she preferred to donate," to which someone might ask, "well, why didn't you ask her?" There is a strong suspicion that the answer would be, "because you didn't want to risk being shown to be wrong." Here, we have a final, if only contingent, difference with the emergency case. In rich countries, it will normally be feasible to make institutional arrangements, like a national donor register, to enable people to register their decisions clearly and unambiguously. But it is a very complicated affair to fine-tune one's living will in such a way that it takes account of all possibly relevant circumstances of emergency. The absence of a living will is rarely an indication that the agent did not care about the decision to be made in an emergency or did not entertain conflicting considerations about it. For that reason, we cannot say in the emergency case that if the person preferred to be treated, he could have made this known in an advance directive. We need a default which, to the best of our knowledge, represents most people's actual interests in most actual cases.

\section{Conclusion}

In the section "A suggestive difference: Does Volenti hold?" I pointed out that consent of the deceased is sufficient to legitimize organ removal, but that even if

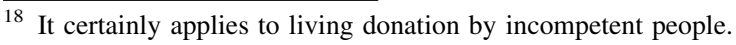


organ removal is a duty, it is not a duty to the deceased. In the emergency case, on the other hand, consent is not enough to legitimize treatment, but if it is required by the health interests of the patient, it is a professional duty owed to him. In the two subsequent sections, I gave an explanation of these facts, in terms of both the interests and the rights of the person involved. In the section on the nature of the interests involved, I argued that the interests people may have in donating or refusing to donate are personal preferences, not basic needs. Such interests do not by themselves create duties for others. In the emergency case, however, basic needs may be at stake, and in that case the doctor has a professional duty of care for them. In the section on the nature of the right involved, I argued that the right to make one's own decisions about donation is an authority-right that cannot be set aside by appeal to the deceased's preferences, however probable their ascription. The correlating duty for others is only to respect the person's authority, not to satisfy his preferences. If he requests aid, one is allowed to provide it, on his authority. In the emergency case, however, the professional duty of the doctor, correlating to the rights of the patient, is not only to respect his authority but also to take care of his basic needs. If the patient has not exercised his authority, the doctor should still do what his needs require. And if the patient exercises his authority by requesting clearly harmful treatment, the doctor's duty not to harm should prevail.

If this is true, in deciding about removal of a person's organs, all we need to do is create sufficient space for the person to make her own decisions, if we can do so without excessive costs. We need not ourselves consider the interests she may have in the fate of her mortal remains if she has been in a position to take care of these interests herself. The only exception to this is her interest in her dead body being treated with respect, an interest protected by a right she may not even be able to waive. Such lack of proper respect, although it is not shown by removing organs from a dead body by itself, can be shown by doing so without authorization. In deciding about the removal of the deceased's organs, if we respect his rights, we have given his interests their full due.

In this article, I have only considered a possible justification of opt-out systems that seems promising at first sight. The discussion has brought to light relevant aspects of the interests and rights involved, which has been my main motive for writing this article. Of course, the negative conclusion I have eventually arrived at does not imply that opt-out systems cannot be defended. In fact my personal view is that they are ethically superior. But the reason is not that they tend to promote the best interests of people who die without having registered either consent or refusal to having their organs removed.

Acknowledgment This article is the result of a discussion with Martin Wilkinson who had defended the "best interests" argument in a draft of a chapter of his book on organ donation, which will shortly be published by Oxford University Press [11]. I am very grateful to him.

Open Access This article is distributed under the terms of the Creative Commons Attribution Noncommercial License which permits any noncommercial use, distribution, and reproduction in any medium, provided the original author(s) and source are credited. 


\section{References}

1. Healy, K. 2006. Precious commodities: Do presumed consent laws raise organ procurement rates? DePaul Law Review 55: 1017-1043.

2. Janssen, A., and S. Gevers. 2005. Explicit or presumed consent and organ donation post mortem: Does it matter? Medicine and Law 24: 575-583.

3. Organ Donation Taskforce. 2008. Organs for transplants. United Kingdom: Department of Health. http://www.dh.gov.uk/en/Publicationsandstatistics/Publications/PublicationsPolicyAndGuidance/ DH_082122. Accessed April 24, 2011.

4. Johnson, E.J., and D. Goldstein. 2004. Defaults and donation decisions. Transplantation 78: 1713-1716.

5. Johnson, E.J., and D. Goldstein. 2003. Do defaults save lives? Science 302: 1338-1339.

6. Thaler, R.H., and C.R. Sunstein. 2008. Nudge: Improving decisions about health, wealth and happiness. New Haven: Yale University Press.

7. Ullmann-Margalit, E. 1983. On presumption. Journal of Philosophy 80: 143-163.

8. den Hartogh, G. 2011. Can organ removal be justified by presumed consent? Journal of Applied Philosophy. doi:10.1111/j.1468-5930.2011.00524.x.

9. den Hartogh, G. 2010. Tacitly consenting to donate one's organs. Journal of Medical Ethics. doi: 10.1136/jme.2010.038463.

10. Price, David. 2009. Human tissue in transplantation and research: A model legal and ethical donation framework. Cambridge: Cambridge University Press.

11. Wilkinson, T.M. Forthcoming. Ethics and the acquisition of organs. Oxford: Oxford University Press.

12. den Hartogh, G. Forthcoming. The role of the relatives in opt-in systems of postmortal organ procurement. Medicine, Health Care and Philosophy.

13. Feinberg, J. 1986. Harm to self. Oxford: Oxford University Press.

14. Westen, P. 2004. The logic of consent: The diversity and deceptiveness of consent as a defense to criminal conduct. Aldershot: Ashgate Publishing Company.

15. Harris, J. 2003. Organ procurement: Dead interests, living needs. Journal of Medical Ethics 29: $130-134$.

16. den Hartogh, G. 2000. Euthanasia: Reflections on the Dutch discussion. In Medical ethics at the dawn of the 21st century, ed. R. Cohen-Almagor, 174-187. New York: New York Academy of Sciences.

17. Gampel, E. 2006. Does professional autonomy protect medical futility judgments? Bioethics 20: 92-104.

18. Wilkinson, T.M. 2005. Individual and family consent to organ and tissue donation: Is the current position coherent? Journal of Medical Ethics 31: 587-590.

19. den Hartogh, G. 2000. Priorities in health care: Why the search for principles fails. In The good life as a public good, ed. G. den Hartogh, 107-118. Dordrecht: Kluwer Academic Publishers.

20. Rawls, J. 1971. Theory of justice. Cambridge: Harvard University Press.

21. Rawls, J. 1982. Social unity and primary goods. In Utilitarianism and beyond, ed. A. Sen and B. Williams, 159-186. Cambridge: Cambridge University Press.

22. Scanlon, T.M. 1975. Preference and urgency. Journal of Philosophy 72: 655-669.

23. Dworkin, R.M. 2000. Sovereign virtue: The theory and practice of equality. Cambridge: Harvard University Press.

24. Sumner, L.W. 1987. The moral foundations of rights. Oxford: Clarendon Press.

25. Griffin, J. 2008. On human rights. Oxford: Oxford University Press.

26. Kluge, E.H. 2000. Improving organ donation rates: Various proposals and their ethical validity. Health Care Analysis 8: 179-195.

27. Wilkinson, T.M. 2007. Individual and family decisions about organ donation. Journal of Applied Philosophy 24: 26-40. 